\title{
Cytoplasmic BRMS1 expression in malignant melanoma is associated with increased disease- free survival
}

\author{
Ana Slipicevic ${ }^{1}$, Ruth Holm¹, Elisabeth Emilsen ${ }^{1}$, Anne Katrine Ree Rosnes ${ }^{1}$, Danny R Welch²,
} Gunhild M Mælandsmo $0^{3,4}$ and Vivi Ann Flørenes ${ }^{1 *}$

\begin{abstract}
Background/aims: Breast cancer metastasis suppressor 1 (BRMS1) blocks metastasis in melanoma xenografts; however, its usefulness as a biomarker in human melanomas has not been widely studied. The goal was to measure BRMS1 expression in benign nevi, primary and metastatic melanomas and evaluate its impact on disease progression and prognosis.
\end{abstract}

Methods: Paraffin-embedded tissue from 155 primary melanomas, 69 metastases and 15 nevi was examined for BRMS1 expression using immunohistochemistry. siRNA mediated BRMS1 down-regulation was used to study impact on invasion and migration in melanoma cell lines.

Results: A significantly higher percentage of nevi (87\%), compared to primary melanomas (20\%) and metastases $(48 \%)$, expressed BRMS1 in the nucelus ( $p<0.0001)$. Strong nuclear staining intensity was observed in $67 \%$ of nevi, and in $9 \%$ and $24 \%$ of the primary and metastatic melanomas, respectively $(p<0.0001)$. Comparable cytoplasmic expression was observed (nevi; 87\%, primaries; 86\%, metastases; 72\%). However, a decline in cytoplasmic staining intensity was observed in metastases compared to nevi and primary tumors $(26 \%, 47 \%$, and $58 \%$, respectively, $\mathrm{p}<$ 0.0001). Score index (percentage immunopositive celles multiplied with staining intensity) revealed that high cytoplasmic score index $(\geq 4)$ was associated with thinner tumors $(p=0.04)$, lack of ulceration $(p=0.02)$ and increased disease-free survival $(p=0.036)$. When intensity and percentage BRMS1 positive cells were analyzed separately, intensity remained associated with tumor thickness $(p=0.024)$ and ulceration $(p=0.004)$ but was inversely associated with expression of proliferation markers (cyclin D3 $(p=0.008)$, cyclin A $(p=0.007)$, and $\left.\mathrm{p} 21^{\text {Waf1/Cip1 }}(p=0.009)\right)$. Cytoplasmic score index was inversely associated with nuclear $p$-Akt $(p=0.013)$ and positively associated with cytoplasmic $p$-ERK1/2 expression $(p=0.033$ ). Nuclear BRMS1 expression in $\geq 10 \%$ of primary melanoma cells was associated with thicker tumors $(p=0.016)$ and decreased relapse-free period $(p=$ 0.043). Nuclear BRMS1 was associated with expression of fatty acid binding protein 7 (FABP7; $p=0.011$ ), a marker of invasion in melanomas. In line with this, repression of BRMS1 expression reduced the ability of melanoma cells to migrate and invade in vitro.

Conclusion: Our data suggest that BRMS1 is localized in cytoplasm and nucleus of melanocytic cells and that cellular localization determines its in vivo effect. We hypothesize that cytoplasmic BRMS1 restricts melanoma progression while nuclear BRMS1 possibly promotes melanoma cell invasion.

Please see related article: http://www.biomedcentral.com/1741-7015/10/19

\footnotetext{
* Correspondence: Vivi.Ann.Florenes@radiumhospitalet.no

'Department of Pathology, Oslo University Hospital, The Norwegian Radium

Hospital, Oslo, Norway

Full list of author information is available at the end of the article
}

\section{() Biomed Central}

(c) 2012 Slipicevic et al; licensee BioMed Central Ltd. This is an Open Access article distributed under the terms of the Creative Commons Attribution License (http://creativecommons.org/licenses/by/2.0), which permits unrestricted use, distribution, and reproduction in any medium, provided the original work is properly cited. 


\section{Introduction}

Although melanomas accounts for only $4 \%$ of all dermatological cancers, they are responsible for approximately $80 \%$ of skin cancer-related deaths. In early stages, melanomas can be treated surgically and 5-year survival rate exceed $80 \%$. However, less than $15 \%$ of patients having metastatic disease (stage IV) can expect to survive 5 years as there are few or no therapeutic options. The molecular mechanisms responsible for melanoma development and progression are not completely understood. Thus, novel diagnostic and prognostic biomarkers as well as improved treatment strategies are urgently needed [1].

Breast cancer metastasis suppressor 1 (BRMS1) was originally identified following differential expression comparisons of chromosome 11 microcell hybrids in a human breast carcinoma cell line and was further mapped to chromosome fragment $11 \mathrm{q} 13$, a region frequently altered in melanomas [2]. Re-expression of BRMS1 in human breast, non-small cell lung (NSCL) and ovarian carcinomas and in melanoma cell lines resulted in marked reduction of metastasis without blocking orthotopic tumor growth [3].

Although BRMS1 has been described as a predominantly nuclear protein, it has recently become clear that it is also localized in the cytoplasm [4,5]. As part of the Sin3:histone deacetylase transcription complex [6], BRMS1 affects metastasis by directly or indirectly repressing expression of pro-metastatic genes and enhancing the expression of other anti-metastatic genes [7]. Furthermore, BRMS1 differentially regulates cancer cell responses to growth factor signaling. Thus, BRMS1 reduces downstream PI3-kinase/Akt signaling by altering phosphoinositide pools and/or by inhibiting epidermal growth factor receptor expression [8]. BRMS1 also represses NF- $\kappa \mathrm{B}$ transcriptional activity, urokinase-type plasminogen activator and osteopontin [9] expression, as well as upregulates expression of anti-metastatic microRNA [10]. In breast, ovarian and NSCL carcinomas, BRMS1 suppresses metastasis by inhibiting growth initiation at secondary sites (i.e., colonization) without preventing primary tumor growth $[11,12]$. In NSCLC, BRMS1 expression decreased migration and invasion [12]. Similarly, melanoma cells re-expressing BRMS1 were less invasive and had restored intercellular communication [13].

In a subgroup of patients suffering from breast cancer, loss of tumor expression of BRMS1 protein was associated with reduced disease-free survival [14]. Furthermore, a shift from nuclear to cytoplasmic BRMS1 expression was found associated with highly proliferative estrogen receptor negative breast cancers [4]. In NSCLC, expression of BRMS1 protein was associated with increased patient survival [12]. Recently, Li et al. [15] observed decreased BRMS1 protein in metastatic melanomas compared to benign nevi and primary tumors as well as an association with tumor stages and worse prognosis. In contrast to these findings, Kelly et al. [16] found no correlation between BRMS1 mRNA level and breast cancer metastasis to regional lymph nodes, while Lombardi et al. [17] showed that high BRMS1 mRNA expression correlates with poor prognosis for patients with breast cancer. Although the mRNA findings are interesting, we have previously reported that mRNA and protein levels for BRMS1 do not always correlate [18]; therefore, interpretation should be done with caution. Nonetheless, although recent literature suggest that BRMS1 may play roles during tumor progression other than the metastasis suppressor function originally suggested, this study was undertaken to investigate the importance of BRMS1 expression and subcellular localization on melanoma progression.

\section{Materials and methods}

\section{Clinical melanoma specimens}

Formalin-fixed, paraffin-embedded tissue from 155 primary melanomas and 69 metastases, as well as 15 benign nevi, was examined for expression of BRMS1 protein. Of the primaries, 93 were classified as superficial spreading (SSM) and 62 as nodular melanoma (NM). Clinical follow-up was available for all patients. The study was approved by the Regional Committee for medical Research Ethics in Norway.

\section{Immunohistochemical analysis}

Three- $\mu \mathrm{m}$ sections made from formalin-fixed paraffin embedded tissues were immunostained using the Dako EnVision $^{\mathrm{TM}}+$ system (K8012, Dako Cooperation, CA, USA). Deparaffinization, rehydration and target retrieval were performed in one operation in a Dako PT-link and EnVision $^{\mathrm{TM}}$ Flex target retrieval solution with high $\mathrm{pH}$. To block endogenous peroxidase the sections were treated with Dako blocking reagent for 5 minutes. Sections were incubated with monoclonal BRMS1 antibody (clone 3a1.21) (supplied by Dr. Welch) diluted 1:500 (2

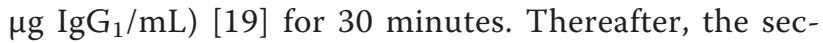
tions were incubated with Dako EnVision ${ }^{\mathrm{TM}}$ FLEX+ mouse linker for 15 minutes followed by incubation with Dako EnVision ${ }^{\text {TM }}$ FLEX/HRP for an additional 30 minutes. For visualization of staining, the sections were treated with AEC+ High sensitivity Substrate Chromogen Ready-to-use (K3469, Dako) (paraffin-embedded tissue) or 3'3-diaminobenzidine tetra-hydrochloride (DAB) (cell lines), counterstained with haematoxylin and mounted from water in Dako Aqueous Mounting 
Medium Ready-to-use. Sections from normal skin with known expression of BRMS1 was used as positive control, whereas negative controls included substitution of monoclonal antibody with mouse myeloma protein of the same subclass and concentration as the monoclonal antibody. Four semi-quantitative classes were used to describe staining intensity (absent, 0; weak, 1; moderate, 2; strong, 3) and percentage of positive tumor cell: absent, $0 ;<10 \%, 1 ; 10-50 \%, 2 ;>50 \%$, 3). By multiplying intensity score with extent score, a score index was calculated ranging from 0 to 9 . Staining in cytoplasm and nucleus were evaluated separately. BRMS1 expression in more than $10 \%$ of the tumor cells was considered as high percentage, while moderate and strong staining intensity were considered as strong. Similarly, a score index of $\geq 4$ was considered as high. Immunohistochemical staining of cyclin D1, cyclin D3, cyclin A, p21 Waf1/ ${ }^{\text {Cip } 1}$ p2 $7^{\text {Kip1 }}$, p-ERK1/2, p-Akt, and FABP7 has been performed previously [20-26].

\section{Cell cultures and small interfering RNA (siRNA) transfection}

The WM239 cell line was kindly provided by Dr. Meenhard Herlyn, (Wistar Institute, Philadelphia, PA) whereas the FEMX-1 cell line was established from a lymph node metastasis obtained from a melanoma patient treated at the Norwegian Radium Hospital, Oslo University Hospital [27]. $1 \times 10^{6}$ cells were plated 24 hrs prior to transfection in T75 culture flasks containing RPMI 1640 medium (Lonza, Verviers, Belgium) supplemented with $5 \%$ foetal bovine serum (FBS) (PAA Laboratories, GMbH, Austria) and $2 \mathrm{mM}$ L-glutamine (GibcoBRL, Paisley, UK). The cells were transfected with 25 nM siRNA targeting BRMS1 (OligoID: HSS177871) or stealth RNAi siRNA negative control in $37.5 \mathrm{uL}$ Lipofectamine 2000 according to the manufactures instructions (Invitrogen, Carlsbad, CA). The siRNA/ lipofectamine 2000 mixture was added in a total of 10 mL OptiMEM to each flask (all reagents and siRNA were from Invitrogen. Six hrs after transfection, medium was replaced with $10 \mathrm{~mL}$ complete medium and $1 \mathrm{~mL}$ $\left[{ }^{3} \mathrm{H}\right]$ Thymidine (ARC St. Louis, MO) was added to the cell cultures for migration and invasion assays. Twentyfour hrs thereafter, the cells were detached by trypsinization, counted and seeded in invasion chambers.

\section{Quantitative real time RT-PCR}

For mRNA expression analyses, the cells were detached 48 hrs after treatment with siRNA. Total RNA was extracted using Trizol reagent (Invitrogen,) according to manufacturer's description and reverse transcribed with the high capacity cDNA reverse transcription kit (Applied Biosystems, Foster City, CA) using random primers. The real time RT-PCR analyses were performed as previously described [26] with TaqMan Gene Expression Assays (Hs00363036_m1 BRMS1, Hs99999908_m1 GUSB, Applied Biosystems). The relative BRMS1 mRNA expression levels were normalized against housekeeping gene beta-glucuronidase (GUSB). Each sample was run in triplicate. The mean from three independent experiments was calculated.

\section{Migration and invasion assays}

Migration and invasive properties were evaluated in a 24 well transwell chamber assay, $8 \mu \mathrm{M}$ pore size (Costar, Cambridge, MA). For analyzing invasiveness, the filters were coated with $25 \mu \mathrm{g} /$ filter Matrigel (BD Biosciences, Bedford, MA) whereas migration was analyzed using uncoated filters. $5 \times 10^{4}\left[{ }^{3} \mathrm{H}\right]$ Thymidine-labeled cells in $100 \mu \mathrm{L}$ RPMI 1640 medium were applied in the upper compartments, in triplicate wells. The lower compartments were supplied with $600 \mu \mathrm{L}$ RPMI 1640 medium and 5\% FBS as chemo attractant. After 48 hrs, the cells on the upper and lower parts of the filters were removed separately using cotton-tipped swabs, and incorporated $\left[{ }^{3} \mathrm{H}\right]$ Thymidine was counted in a liquid scintillation analyzer (Packard Instrument Company, Chicago, IL). Migration/invasion was assessed as the ratio of counts obtained from the lower compartments compared to total counts of both compartments.

\section{Statistical analysis}

A comparison between variables was performed using the $\chi^{2}$ test or the Fisher exact test. The relationship between BRMS1 expression and mean tumor thickness was evaluated using the Mann-Whitney 2-sample test. Kaplan- Meier survival estimates and log-rank tests were used to evaluate the survival data. Two-tailed paired Student's t-test was used to evaluate the in vitro results. A p-value of less than 0.05 was considered statistically significant.

\section{Results}

Protein expression of BRMS1 was analyzed by immunohistochemistry in a panel of paraffin-embedded benign nevi and primary and metastatic melanoma tissues as well as in two melanoma cell lines. Heterogeneous cytoplasmic and/or nuclear expression was observed. However, BRMS1 immunoreactivity was not found to accumulate in specific parts of the tumor biopsies. The results are summarized in Table 1 and illustrated in Figure 1. A significantly higher percentage of benign nevi (87\%) as compared to primary $(20 \%)$ and metastatic melanoma (48\%), expressed BRMS1 in the nucleus ( $\mathrm{p}<$ $0.0001)$. Cytoplasmic expression was found in $87 \%$ of benign nevi and in $86 \%$ and $72 \%$ of primaries and metastases, respectively. When staining intensity was evaluated separately, strong nuclear intensity was 
Table 1 Expression of BRMS1 according to number of positive cases, intensity and subcellular localization

\begin{tabular}{|c|c|c|c|c|c|c|c|}
\hline & \multicolumn{3}{|c|}{${ }^{1}$ No. positive (\%) } & \multicolumn{2}{|c|}{ Intensity (\%) } & \multicolumn{2}{|c|}{ Score index (\%) } \\
\hline & & & & Nucleus & Cytoplasm & Nucleus & Cytoplasm \\
\hline & Total & Nucleus & Cytoplasm & Strong $^{2}$ & Strong & $\mathrm{High}^{3}$ & High \\
\hline Nevi & $15(100)$ & $13(87)$ & $13(87)$ & $10(67)$ & $7(47)$ & $8(53)$ & $1(7)$ \\
\hline $\begin{array}{l}\text { Primary } \\
\text { Melanomas }\end{array}$ & $136(88)$ & $32(20)$ & $134(86)$ & $14(9)$ & $90(58)$ & $7(5)$ & $77(50)$ \\
\hline $\mathrm{SSM}^{4}$ & $83(89)$ & $17(20)$ & $82(88)$ & $7(8)$ & $61(66)$ & $2(2)$ & $54(58)$ \\
\hline $\mathrm{NM}^{5}$ & $53(85)$ & $15(24)$ & $52(84)$ & $7(11)$ & $29(45)$ & $5(8)$ & $23(37)$ \\
\hline Metastases & $62(90)$ & $33(48)$ & $50(72)$ & $17(24)$ & $18(26)$ & $15(22)$ & $13(19)$ \\
\hline
\end{tabular}

${ }^{1}$ Includes all positive cases

${ }^{2}$ Strong staining intensity includes moderate and strong intensity

${ }^{3}$ High score index defined as $\geq 4$

${ }^{4} \mathrm{SSM}$; Superficial spreading melanoma

${ }^{5} \mathrm{NM}$; Nodular melanoma

observed in $67 \%$ of nevi but in only $9 \%$ of primary and $24 \%$ of metastatic tumors ( $<<0.0001)$. Whereas $47 \%$ of the nevi and $58 \%$ of the primaries showed strong cytoplasmic staining intensity, a significant decline was observed in the metastases $(26 \%$; $<<0.0001)$. When score index (percentage of immunoreactive cells multiplied with staining intensity) was used as readout, high nuclear score index $(\geq 4)$ was observed in $53 \%$ of nevi as compared to only $5 \%$ of the primary tumors. Interestingly, the opposite was observed for cytoplasmic staining; high cytoplasmic score index was seen in $50 \%$ of the primaries but in only $7 \%$ of the nevi. Nuclear and cytoplasmic score indexes were comparable in the metastases (22\% and $19 \%$, respectively) (Table 1). In melanoma cell lines, BRMS1 was localized mainly in the nucleus, although some cytoplasmic expression was also seen (Figure 1G, H).

\section{Expression of BRMS1 in relation to clinical parameters}

BRMS1 expression levels in superficial spreading and nodular melanomas revealed no obvious differences with regard to score index, number of immunoreactive cells, nor staining intensity (Table 1 ). Moreover, no differences were observed when comparing radial (tumor thickness $<1 \mathrm{~mm}$ ) and vertical (tumor thickness $\geq 1$ $\mathrm{mm}$ ) growth phase tumors. (data not shown). High cytoplasmic BRMS1 score index was significantly associated with thinner tumors $(\mathrm{p}=0.040)$, lack of ulceration $(\mathrm{p}=$ $0.020)$, and increased disease-free survival ( $p=0.036$; Table 2 and Figure 2A). However, only staining intensity remained associated with tumor thickness $(\mathrm{p}=0.024)$ and ulceration $(\mathrm{p}=0.004)$ when intensity and percentage BRMS1 immunoreactive cells were analyzed separately (Table 3 ). Tumors with high percentage of cells expressing nuclear BRMS1 were thicker $(p=0.016)$ (Table 4$)$ and had shorter relapse-free survival $(\mathrm{p}=$ 0.043) (Figure 2B). Neither nuclear score index nor staining intensity were associated with any of the examined clinical parameters (data not shown). Neither cytoplasmic nor nuclear BRMS1 expression had impact on overall survival (data not shown).

\section{Relationship between cytoplasmic BRMS1 expression and} markers of proliferation and signal transduction

Since this panel of melanoma tissues has been previously analyzed for factors involved in cell proliferation $[20-22,24]$, it was of interest to examine the relationship between BRMS1 expression and the levels of those factors. A significant inverse correlation between cytoplasmic BRMS1 score index and cyclin D3 expression was observed $(p=0.001)$ (Table 2). Interestingly, however, when analyzing percentage cytoplasmic BRMS1 positivity and staining intensity separately, a strong inverse association was found between staining intensity and cyclin D3 $(\mathrm{p}=0.008)$, cyclin A $(\mathrm{p}=0.007)$, and $\mathrm{p} 21^{\text {Waf1/ }}$ ${ }^{\text {Cip1 }}(\mathrm{p}=0.009)$ (Table 3). Furthermore, although not significant, we found a negative association between BRMS1 staining intensity and Ki67 expression ( $\mathrm{p}=$ 0.068) (Table 3). No correlation was seen between cytoplasmic BRMS1 staining intensity and cyclin D1 or p2 $7^{\text {Kip1 }}$ expression (data not shown). Nuclear BRMS1 expression was not associated with markers of proliferation (data not shown).

It was demonstrated previously that expression of BRMS1 is correlated with activation of the PI3-kinase/ Akt and NF- $\kappa$ B signaling pathways $[8,9,28]$. Here we present results showing that cytoplamic score index is inversely correlated to nuclear $\mathrm{p}$-Akt expression ( $\mathrm{p}=$ $0.013)$, but positively associated with expression of activated cytoplasmic ERK1/2 ( $\mathrm{p}=0.033)$ (Table 2).

\section{Nuclear BRMS1 expression is associated with invasive properties}

We have recently demonstrated an association between protein expression of fatty acid binding protein 7 (FABP7) and proliferation and invasion of melanoma 


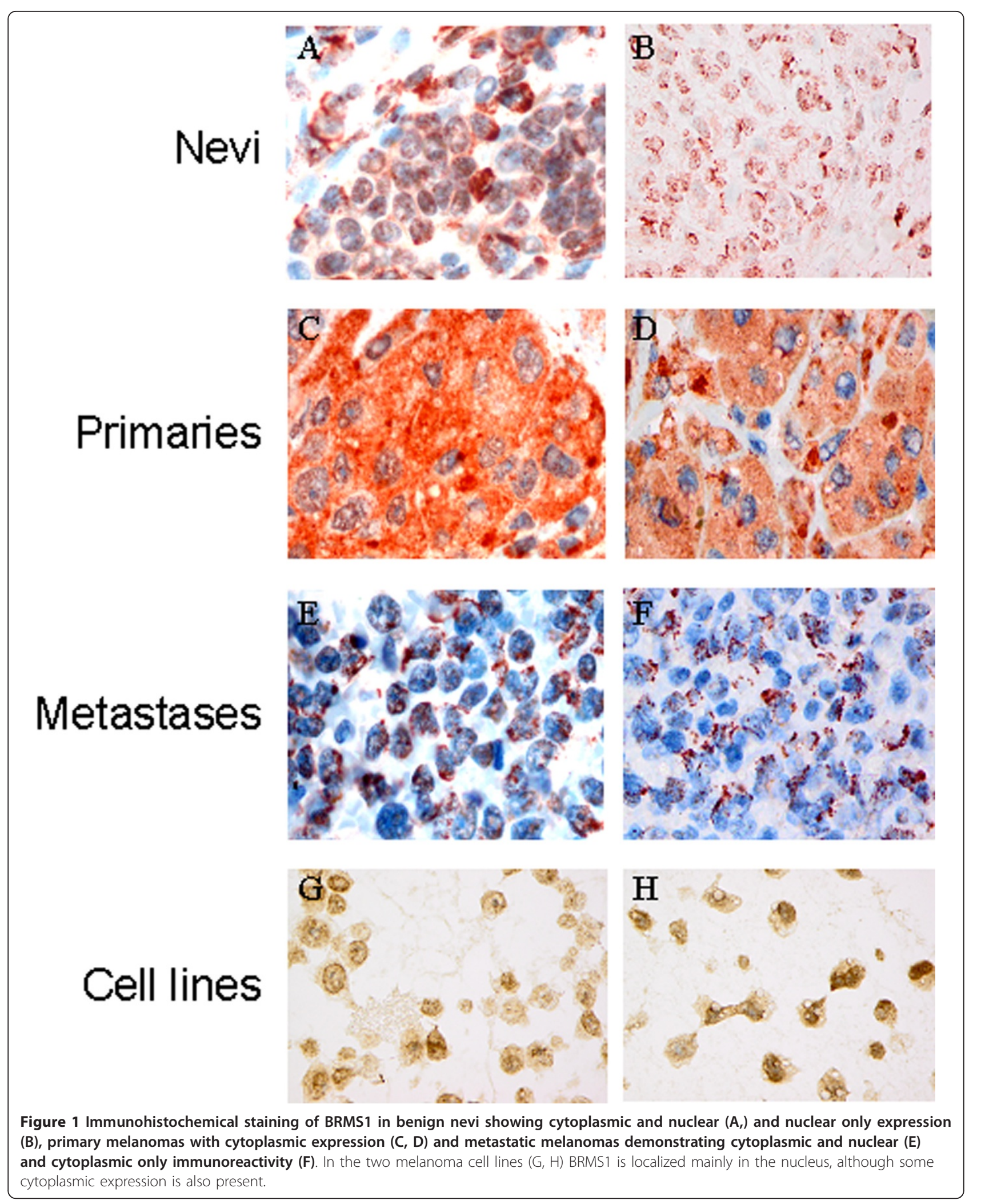


Table 2 Relationship between cytoplasmic BRMS1 score index, ulceration, tumor thickness, cyclin D3 and activation of ERK1/2 and Akt

\begin{tabular}{|c|c|c|c|c|}
\hline \multirow[b]{2}{*}{ Clinical parameter } & \multirow[b]{2}{*}{ Expression } & \multicolumn{2}{|c|}{ Cytoplasmic BRMS1 score index } & \multirow[b]{2}{*}{$\mathbf{P}$} \\
\hline & & Low & High $^{a}$ & \\
\hline \multirow[t]{2}{*}{ Mean tumor depth $(\mathrm{mm})$} & & $3.60(3.29)^{b}$ & $2.42(2.46)$ & 0.040 \\
\hline & No & 41 & 53 & \\
\hline Ulceration & Yes & 30 & 16 & 0.020 \\
\hline \multicolumn{5}{|l|}{ Marker } \\
\hline \multirow[t]{3}{*}{ Cyclin D3 } & Low & 42 & 57 & \\
\hline & High & 32 & 12 & 0.001 \\
\hline & Low & 43 & 29 & \\
\hline \multirow[t]{2}{*}{ Cytoplasmic p-ERK } & High & 32 & 46 & 0.033 \\
\hline & Low & 46 & 59 & 0.013 \\
\hline Nuclear p-Akt & High & 26 & 12 & \\
\hline
\end{tabular}

aHigh score index defined as $\geq 4$

Low protein expression was defined as immunoreactivity in less than $5 \%$ (cyclin D3) [21]

in $<50 \%$ of the tumor cells (p-Akt) [25], or total lack of expression (p-ERK) [23]

${ }^{\mathrm{b}} \mathrm{SD}$

cells [26]. When examining the melanoma panel for a possible association between BRMS1 and FABP7, a significant correlation between nuclear BRMS1 expression (percentage of immunoreactive cells) and the level of FABP7 ( $\mathrm{p}=0.011)($ Table 4$)$ was observed.

To examine in more detail whether BRMS1 affects migration and invasion of melanoma cells we transiently down-regulated BRMS1 expression using siRNA in two metastatic melanoma cell lines (WM239, FEMX-1) (Figure 3A) and performed a transwell chamber invasion/ migration assay. As demonstrated in Figure 3B, repression of BRMS1 significantly reduced invasion in both cell lines (WM239; $\mathrm{p}=0.047$, FEMX-1; $\mathrm{p}=0.016$ ) whereas migration was only repressed in the WM239 cells (WM239; $\mathrm{p}=0.013$, FEMX-1; $\mathrm{p}=0.43$ ).

\section{Discussion}

Immunohistochemistry was applied to examine the level of BRMS1 protein in a panel of benign nevi and primary and metastatic melanomas in order to evaluate the impact of altered expression on clinical outcome. In accordance with previous studies demonstrating higher mRNA and/or nuclear BRMS1 protein expression in normal or benign tissues as compared to malignant tumors $[4,12,29]$, BRMS1 was highly expressed in the nucleus of benign nevi whereas only a minor fraction of

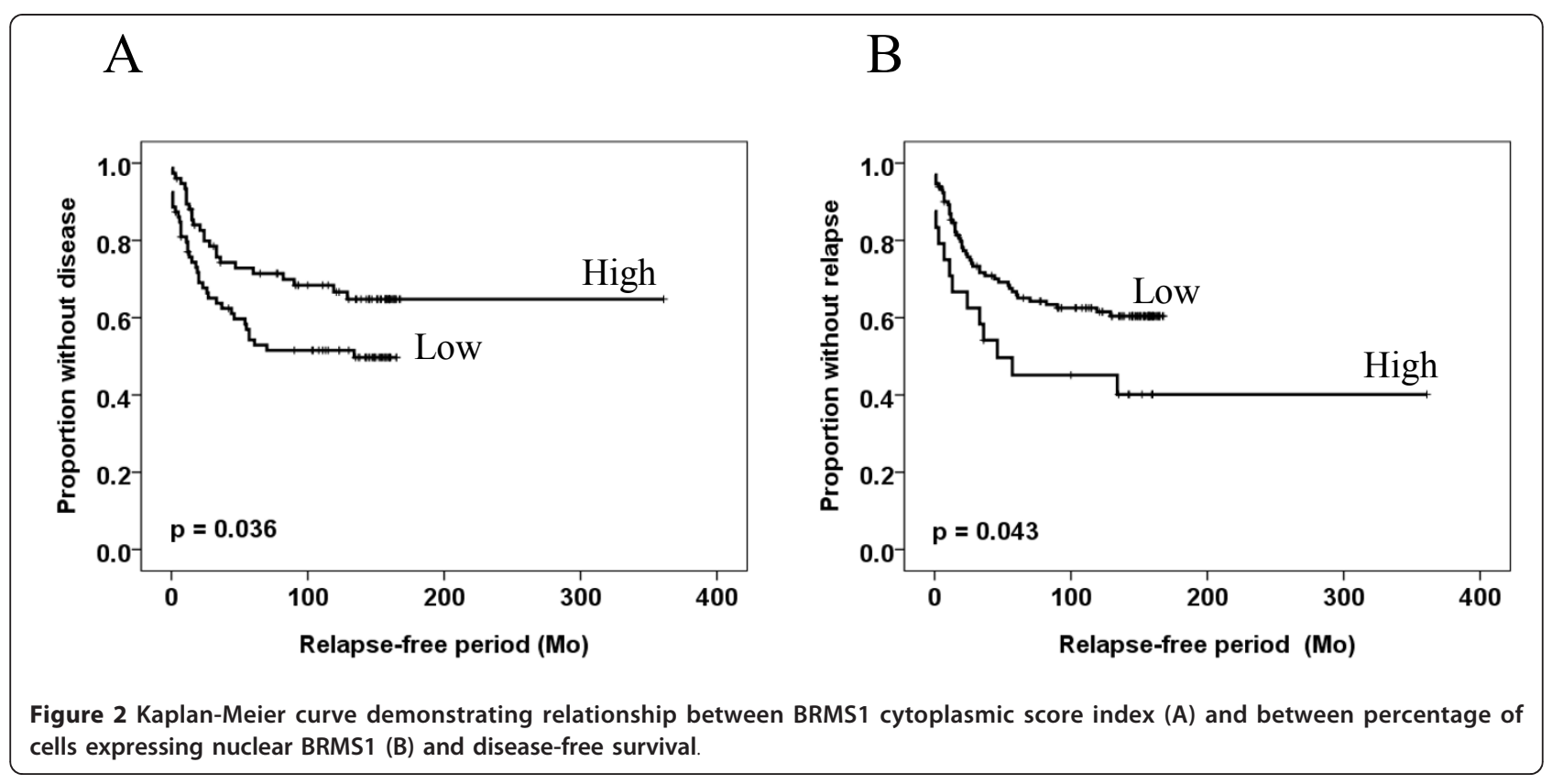


Table 3 Relationship between intensity of BRMS1 expression, ulceration, tumor thickness and markers of proliferation

\begin{tabular}{|c|c|c|c|c|}
\hline \multirow[b]{2}{*}{ Clinical parameter } & \multirow[b]{2}{*}{ Expression } & \multicolumn{2}{|c|}{$\begin{array}{l}\text { Intensity of } \\
\text { cytoplasmic } \\
\text { BRMS1 staining }\end{array}$} & \multirow[b]{2}{*}{$P$} \\
\hline & & Weak & Strong $^{\mathrm{a}}$ & \\
\hline $\begin{array}{l}\text { Mean tumor depth } \\
(\mathrm{mm})\end{array}$ & & $\begin{array}{l}3.26(3.11) \\
b\end{array}$ & $\begin{array}{l}1.92 \\
(1.89)\end{array}$ & 0.024 \\
\hline \multirow[t]{2}{*}{ Ulceration } & No & 71 & 23 & \\
\hline & Yes & 44 & 2 & 0.004 \\
\hline \multicolumn{5}{|l|}{ Marker } \\
\hline & Low & 53 & 19 & \\
\hline \multirow[t]{2}{*}{ Cyclin A } & High & 65 & 6 & 0.007 \\
\hline & Low & 70 & 20 & \\
\hline Ki67 & High & 48 & 5 & 0.068 \\
\hline \multirow[t]{3}{*}{ Cyclin D3 } & Low & 76 & 23 & \\
\hline & High & 42 & 2 & 0.008 \\
\hline & Low & 32 & 17 & \\
\hline p21 & High & 31 & 3 & 0.009 \\
\hline
\end{tabular}

a Low protein expression was defined as immunoreactivity in less than $5 \%$ of the tumor cells

(cyclin A, Ki67, cyclin D3, p21)[21,22,24]

${ }^{\mathrm{b}} \mathrm{SD}$

primary melanomas or metastases showed a similar expression profile. Our findings also partially agree with the study by Li et al. [15] who observed a decline in nuclear BRMS1 expression from dysplastic nevi to primary melanomas. A possible explanation for the more dramatic decline in our study may be that, in the previous study, malignant lesions were compared to dysplastic nevi while benign nevi of compound and intradermal subtypes where utilized in our investigations. Thus, it may be speculated that loss of nuclear BRMS1 expression is an early event, distinguishing common and dysplastic nevi.

Although BRMS1 has been recognized as a mainly nuclear protein, Rivera et al. [5] recently showed that BRMS1 contains both nuclear import and export signals,

Table 4 Relationship between nuclear BRMS1 expression, tumor thickness, and expression of FABP7

\begin{tabular}{|c|c|c|c|c|}
\hline \multirow[b]{2}{*}{ Clinical parameter } & \multirow[b]{2}{*}{ Expression } & \multicolumn{2}{|c|}{$\begin{array}{l}\text { Expression of } \\
\text { nuclear BRMS1 }\end{array}$} & \multirow[b]{2}{*}{$\mathbf{P}$} \\
\hline & & Low $^{a}$ & High & \\
\hline $\begin{array}{l}\text { Mean tumor depth } \\
(\mathrm{mm})\end{array}$ & & $\underset{c}{2.72(2.69)}$ & $\begin{array}{l}4.70 \\
(3.85)\end{array}$ & 0.016 \\
\hline \multicolumn{5}{|l|}{ Marker } \\
\hline & Low $^{b}$ & 52 & 1 & \\
\hline FABP7 & High & 74 & 15 & 0.011 \\
\hline
\end{tabular}

and implied that nuclear-cytoplasmic shuttling may represent a novel mechanism for altering the activity or function of BRMS1. The data in this study and a recent immunocytochemistry report in breast cancer [4] are consistent with that hypothesis. During melanocyte transformation and progression, BRMS1 appears to relocalize from the nucleus to the cytoplasm. Additionally, cytoplasmic staining intensity appeared to have a more pronounced impact than number of immunoreactive cells, suggesting that the level of BRMS1 protein has to reach a threshold level to have an effect on cellular behavior. Although there was no obvious difference in the percentage of tumor cells expressing BRMS1 in the cytoplasm, there was a clear decline in staining intensity in metastases as compared to nevi and primary tumors. Our findings are, however, in contrast to the study by $\mathrm{Li}$ et al., [15] who observed predominantly nuclear BRMS1 expression in benign and malignant melanocytic cells. One explanation for this discrepancy may be the use of different antigen retrieval and detection methods.

Frolova et al. [4] reported that cytoplasmic BRMS1 was associated with increased proliferation in estrogen receptor-negative breast cancers. In contrast, the melanoma samples used here show that cytoplasmic expression of BRMS1 is inversely associated with markers of proliferation, cyclin D3, cyclin A, Ki67, p21 Waf1/Cip1. When coupled with our previously demonstrated associations between cell cycle regulators, numbers of mitosis and disease progression [21,22,24], the data presented further strengthen the hypothesis that cytoplasmic BRMS1 is associated with a less aggressive melanoma phenotype (i.e., thinner tumors, less ulcerated, longer survival).

ERK1/2, when sequestered in the cytoplasm, has been suggested to prevent transcription of pro-survival and proliferative proteins as well as enhance the activity of pro-apoptotic cytoplasmic proteins [30]. Furthermore, whereas Gayer et al. [31] recently suggested that excluding ERK1/2 from the nucleus inhibits proliferation, Jovanovic et al.[32] observed that the presence of activated ERK1/2 in the cytoplasm of melanomas was associated with better prognosis. In line with this, we demonstrated a strong positive association between BRMS1 and activated ERK1/2 when both were localized in the cytoplasm. Moreover, we also observed a strong inverse association between cytoplasmic BRMS1 expression and accumulation of activated p-Akt in the nucleus. Prior studies observed a negative association between BRMS1 and activation of PI3-kinase/Akt signaling [28,33], which is consistent with the well documented evidence that PI3-kinase/Akt signaling affects numerous steps of the metastatic cascade, including proliferation, apoptosis, migration and invasion [34]. In thyroid cancer, nuclear localization of activated Akt was associated with tumor 

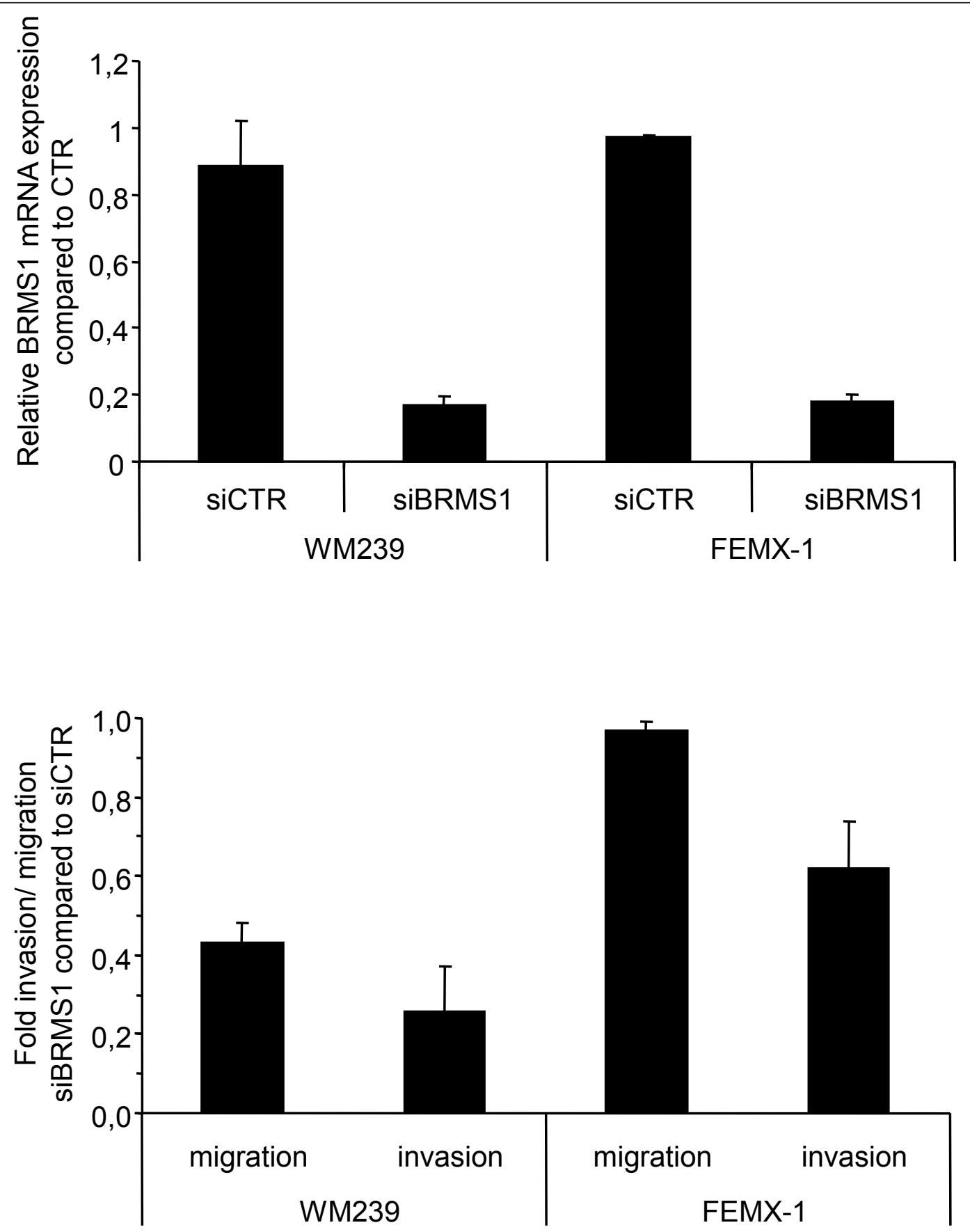

Figure 3 Effect of BRMS1 on migration and invasion of melanoma cells. BRMS1 expression was transiently down-regulated using siRNA in the metastatic melanoma cell lines WM239 and FEMX-1 (A) and analyzed for migration and invasion ability in a transwell chamber assay (B). Bars represent mean ratio of cells \pm SE of cells in the lower compartment compared to total number of cells in both compartments from at least three independent biological experiments. WM239: invasion; $p=0.047$, migration; $p=0.013$, FEMX-1; invasion; $p=0.016$, migration; $p=0.43$.

invasion and metastasis [35]. Together these results suggest that cytoplasmic BRMS1 may at least partly negatively regulate melanoma progression and metastasis through sequestering of activated ERK1/2 in the cytoplasm and by preventing accumulation of nuclear active Akt.
In contrast to the results obtained in another melanoma cohort [15], as well as in breast [14] and NSCL cancers [12] our study showed that high nuclear expression of BRMS1 was associated with more aggressive tumors and shorter disease-free survival. The higher nuclear expression of BRMS1 found in benign nevi than in primary 
melanomas or metastases seems contradictory to the association to prolonged disease-free survival for patients having low nuclear tumor expression of BRMS1. As yet, we are unable to explain this phenomenon, but benign nevi are commonly terminal lesions as opposed to melanomas. Thus, the molecular events regulating these processes might differ. In this regard it has been shown that mutated B-Raf plays a role in inducing senescence in melanocytes, whereas in melanomas it contributes to oncogenesis [36]. Furthermore, in a recent study we showed that expression of fatty acid binding protein 7 (FABP7) is higher in benign nevi than in melanomas, still FABP7 was suggested to contribute to disease progression, most likely by increasing tumor cell invasion [26]. Interestingly, we observed a strong positive association between nuclear BRMS1 and FABP7 expression, suggesting that nuclear BRMS1 may, in fact, increase the invasive potential. In support of this, we showed that down-regulation of BRMS1 in two metastatic melanoma cell lines, expressing predominantly nuclear BRMS1, reduced the invasive ability.

Although it has not yet been verified at the protein level, the mRNA for various splice variants that are differently expressed in metastatic and non-metastatic breast cancer cell lines have been identified $[18,37]$. Thus, it may be speculated that benign nevi and primary and metastatic melanomas express different BRMS1 variants with different biological functions.

\section{Conclusion}

The BRMS1 metastasis suppressor is localized in both the cytoplasm and nucleus of melanocytic tumors. Cellular localization corresponds to different effects, cytoplasmic BRMS1 appears to restrict tumor progression by negatively affecting cell proliferation, sequestering $\mathrm{p}$ ERK1/2 in the cytoplasm and by preventing accumulation of nuclear p-Akt while nuclear BRMS1 may promote melanoma invasion, perhaps by its association with FABP7. Clearly, while BRMS1 may have shared roles in some tumor types, it is apparent that those roles can vary by the cell type from which a tumor arises and also by the tumor microenvironment.

\section{Acknowledgements}

This work was supported by the Norwegian Cancer Society and by Astrid and Birger Torsteds' legacy. The antibodies to BRMS1 were generated using support from the National Cancer Institute (CA87728) and the National Foundation for Cancer Research.

\section{Author details}

'Department of Pathology, Oslo University Hospital, The Norwegian Radium Hospital, Oslo, Norway. ${ }^{2}$ Department of Cancer Biology, The Kansas University Medical Center, Kansas City, USA. ${ }^{3}$ Department of Tumor Biology, Institute for Cancer Research, Oslo University Hospital The Norwegian Radium Hospital, Oslo, Norway. ${ }^{4}$ Department of Pharmacy, Faculty of Health Sciences, University of Tromsø, Tromsø, Norway.

\section{Authors' contributions}

AS and EE optimized and performed the immunohistochemical analyses. $\mathrm{RH}$ evaluated the immunohistochemical staining. EE and AKRR performed the siRNA transfections and the invasion and migration assays. VAF conceived the study and drafted the manuscript. GMM participated in the design and coordination of the study whereas DW provided the antibody. All authors have read and approved the final manuscript.

\section{Competing interests}

The authors declare that they have no competing interests.

Received: 24 October 2011 Accepted: 22 February 2012

Published: 22 February 2012

\section{References}

1. Miller AJ, Mihm MC Jr: Melanoma. N Engl J Med 2006, 355:51-65.

2. Robertson G, Coleman A, Lugo TG: A malignant melanoma tumor suppressor on human chromosome 11. Cancer Res 1996, 56:4487-4492.

3. Cook LM, Hurst DR, Welch DR: Metastasis suppressors and the tumor microenvironment. Semin Cancer Biol 2011, 21:113-122.

4. Frolova N, Edmonds MD, Bodenstine TM, Seitz R, Johnson MR, Feng R, et al: A shift from nuclear to cytoplasmic breast cancer metastasis suppressor 1 expression is associated with highly proliferative estrogen receptornegative breast cancers. Tumour Biol 2009, 30:148-159.

5. Rivera J, Megias D, Navas C, Bravo J: Identification of essential sequences for cellular localization in BRMS1 metastasis suppressor. PLOS One 2009, 4:e6433

6. Meehan WJ, Samant RS, Hopper JE, Carrozza MJ, Shevde LA, Workman JL, et al: Breast cancer metastasis suppressor 1 (BRMS1) forms complexes with retinoblastoma-binding protein 1 (RBP1) and the $m \operatorname{Sin} 3$ histone deacetylase complex and represses transcription. J Biol Chem 2004, 279:1562-1569.

7. Rivera J, Megias D, Bravo J: Proteomics-based strategy to delineate the molecular mechanisms of the metastasis suppressor gene BRMS1. $J$ Proteome Res 2007, 6:4006-4018.

8. Cicek M, Fukuyama R, Welch DR, Sizemore N, Casey G: Breast cancer metastasis suppressor 1 inhibits gene expression by targeting nuclear factor-kappaB activity. Cancer Res 2005, 65:3586-3595.

9. Samant RS, Clark DW, Fillmore RA, Cicek M, Metge BJ, Chandramouli KH, et al: Breast cancer metastasis suppressor 1 (BRMS1) inhibits osteopontin transcription by abrogating NF-kappaB activation. Mol Cancer 2007, 6:6.

10. Edmonds MD, Hurst DR, Vaidya KS, Stafford LJ, Chen D, Welch DR: Breast cancer metastasis suppressor 1 coordinately regulates metastasisassociated microRNA expression. Int J Cancer 2009, 125:1778-1785.

11. Hedley BD, Vaidya KS, Phadke P, MacKenzie L, Dales DW, Postenka CO, et al BRMS1 suppresses breast cancer metastasis in multiple experimental models of metastasis by reducing solitary cell survival and inhibiting growth initiation. Clin Exp Metastasis 2008, 25:727-740.

12. Smith PW, Liu Y, Siefert SA, Moskaluk CA, Petroni GR, Jones DR: Breast cancer metastasis suppressor 1 (BRMS1) suppresses metastasis and correlates with improved patient survival in non-small cell lung cancer. Cancer Lett 2009, 276:196-203.

13. Shevde LA, Samant RS, Goldberg SF, Sikaneta T, Alessandrini A, Donahue $\mathrm{HJ}$, et al: Suppression of human melanoma metastasis by the metastasis suppressor gene, BRMS1. Exp Cell Res 2002, 273:229-239.

14. Hicks DG, Yoder BJ, Short S, Tarr S, Prescott N, Crowe JP, et al: Loss of breast cancer metastasis suppressor 1 protein expression predicts reduced disease-free survival in subsets of breast cancer patients. Clin Cancer Res 2006, 12:6702-6708.

15. Li J, Cheng Y, Tai D, Martinka M, Welch DR, Li G: Prognostic significance of BRMS1 expression in human melanoma and its role in tumor angiogenesis. Oncogene 2011, 30:896-906.

16. Kelly LM, Buggy Y, Hill A, O'Donovan N, Duggan C, McDermott EW, et al: Expression of the breast cancer metastasis suppressor gene, BRMS1, in human breast carcinoma: lack of correlation with metastasis to axillary lymph nodes. Tumour Biol 2005, 26:213-216.

17. Lombardi G, Di CC, Capodanno A, lorio MC, Aretini P, Isola P, et al: High level of messenger RNA for BRMS1 in primary breast carcinomas is associated with poor prognosis. Int J Cancer 2007, 120:1169-1178. 
18. Hurst DR, Xie Y, Edmonds MD, Welch DR: Multiple forms of BRMS1 are differentially expressed in the MCF10 isogenic breast cancer progression model. Clin Exp Metastasis 2009, 26:89-96.

19. Hurst DR, Mehta A, Moore BP, Phadke PA, Meehan WJ, Accavitti MA, et al: Breast cancer metastasis suppressor 1 (BRMS1) is stabilized by the Hsp90 chaperone. Biochem Biophys Res Commun 2006, 348:1429-1435.

20. Florenes VA, Maelandsmo GM, Kerbel RS, Slingerland JM, Nesland JM, Holm R: Protein expression of the cell-cycle inhibitor p27Kip1 in malignant melanoma: inverse correlation with disease-free survival. Am J Pathol 1998, 153:305-312.

21. Florenes VA, Faye RS, Maelandsmo GM, Nesland JM, Holm R: Levels of cyclin D1 and D3 in malignant melanoma: deregulated cyclin D3 expression is associated with poor clinical outcome in superficial melanoma. Clin Cancer Res 2000, 6:3614-3620.

22. Florenes VA, Maelandsmo GM, Faye R, Nesland JM, Holm R: Cyclin A expression in superficial spreading malignant melanomas correlates with clinical outcome. J Pathol 2001, 195:530-536.

23. Jorgensen K, Holm R, Maelandsmo GM, Florenes VA: Expression of activated extracellular signal-regulated kinases $1 / 2$ in malignant melanomas: relationship with clinical outcome. Clin Cancer Res 2003, 9:5325-5331.

24. Maelandsmo GM, Holm R, Fodstad O, Kerbel RS, Florenes VA: Cyclin kinase inhibitor p21WAF1/CIP1 in malignant melanoma: reduced expression in metastatic lesions. Am J Pathol 1996, 149:1813-1822.

25. Slipicevic A, Holm R, Nguyen MT, Bohler PJ, Davidson B, Florenes VA: Expression of activated Akt and PTEN in malignant melanomas: relationship with clinical outcome. Am J Clin Pathol 2005, 124:528-536.

26. Slipicevic A, Jorgensen K, Skrede M, Rosnes AK, Troen G, Davidson B, et al: The fatty acid binding protein 7 (FABP7) is involved in proliferation and invasion of melanoma cells. BMC Cancer 2008, 8:276.

27. Fodstad O, Kjonniksen I, Aamdal S, Nesland JM, Boyd MR, Pihl A: Extrapulmonary, tissue-specific metastasis formation in nude mice injected with FEMX-I human melanoma cells. Cancer Res 1988, 48:4382-4388.

28. Vaidya KS, Harihar S, Phadke PA, Stafford LJ, Hurst DR, Hicks DG, et al: Breast cancer metastasis suppressor-1 differentially modulates growth factor signaling. J Biol Chem 2008, 283:28354-28360.

29. Zhang S, Lin QD, DI W: Suppression of human ovarian carcinoma metastasis by the metastasis-suppressor gene, BRMS1. Int J Gynecol Cancer 2006, 16:522-531.

30. Mebratu $Y$, Tesfaigzi Y: How ERK1/2 activation controls cell proliferation and cell death: Is subcellular localization the answer? Cell Cycle 2009, 8:1168-1175.

31. Gayer CP, Craig DH, Flanigan $T L$, Reed TD, Cress DE, Basson MD: ERK regulates strain-induced migration and proliferation from different subcellular locations. J Cell Biochem 2010, 109:711-725.

32. Jovanovic B, Krockel D, Linden D, Nilsson B, Egyhazi S, Hansson J: Lack of cytoplasmic ERK activation is an independent adverse prognostic facto in primary cutaneous melanoma. J Invest Dermatol 2008, 128:2696-2704.

33. DeWald DB, Torabinejad J, Samant RS, Johnston D, Erin N, Shope JC, et al: Metastasis suppression by breast cancer metastasis suppressor 1 involves reduction of phosphoinositide signaling in MDA-MB-435 breast carcinoma cells. Cancer Res 2005, 65:713-717.

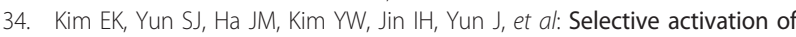
Akt1 by mammalian target of rapamycin complex 2 regulates cancer cell migration, invasion, and metastasis. Oncogene 2011.

35. Vasko V, Saji M, Hardy E, Kruhlak M, Larin A, Savchenko V, et al: Akt activation and localisation correlate with tumour invasion and oncogene expression in thyroid cancer. J Med Genet 2004, 41:161-170.

36. Wajapeyee N, Serra RW, Zhu X, Mahalingam M, Green MR: Oncogenic BRAF induces senescence and apoptosis through pathways mediated by the secreted protein IGFBP7. Cell 2008, 132:363-374.

37. Hurst DR, Welch DR: Unraveling the enigmatic complexities of BRMS1mediated metastasis suppression. FEBS Lett 2011, 585:3185-3190.

\section{Pre-publication history}

The pre-publication history for this paper can be accessed here:

http://www.biomedcentral.com/1471-2407/12/73/prepub doi:10.1186/1471-2407-12-73

Cite this article as: Slipicevic et al:: Cytoplasmic BRMS1 expression in malignant melanoma is associated with increased disease-free survival. BMC Cancer 2012 12:73.

\section{Submit your next manuscript to BioMed Central and take full advantage of:}

- Convenient online submission

- Thorough peer review

- No space constraints or color figure charges

- Immediate publication on acceptance

- Inclusion in PubMed, CAS, Scopus and Google Scholar

- Research which is freely available for redistribution 